\title{
Experimental Valuation Diagnostics of Hydrous Ethanol Sprays Formed by a Blurry Injector
}

\author{
Claudia Gonçalves de Azevedo", José Carlos de Andrade, Fernando de Souza Costa
}

\begin{abstract}
Concerns about the rising fuel price and environmental changes have led to the search for alternative fuels and energy sources. The interest in improving the performance of power generation, with the aim of reducing costs, increasing operating efficiency, and reducing the emissions of pollutants, has driven the scientific community to work on new burning technologies. Flameless combustion is one of the best alternative new technologies for a clean and efficient one. The burning of liquid fuels in power generation and propulsion systems depends on the effective atomization to increase the surface area of the fuel and thus to achieve high rates of mixing and evaporation. This work described the spray characteristics of hydrous ethanol in a blurry injector for applications in a flameless compact combustion chamber. The experimental results are obtained over a range of relatively low flow rates with different air-toliquid mass flow ratios.
\end{abstract}

KEYWORDS: Blurry injector, Hydrous Ethanol, Drop size, Discharge coefficients.

\section{INTRODUCTION}

Spray combustion is extensively used in power generation and liquid-fueled rocket engines. In general, before burning, liquid fuels need to be dispersed in small droplets that are rapidly vaporized and mixed with the oxidizer. The atomization process increases the surface area of the fuel, aiming at making the contact area between the fuel and oxidizer higher and, therefore, its rates of mixing and fuel evaporation and in the time available for complete combustion. Effective fuel atomization is essential to minimize emissions of particulate matter $(\mathrm{PM})$, carbon monoxide (CO), unburned hydrocarbons (UHC), and nitric oxides $\left(\mathrm{NO}_{\mathrm{x}}\right)$.

The increasing costs of fossil fuels, environmental concerns, and stringent regulations on fuel emissions have caused a significant interest for the use of biofuels. Ethanol has become an attractive alternative fuel for: it is a renewable energy source, easily available from common biomass sources, biodegradable, contributes to sustainability and is oxygenated, thereby providing the potential to reduce pollutants emissions. Due to its combustion characteristics, it also has been considered as a low polluting liquid propellant for the combustion rocket propulsion application (Gajdeczko et al., 2000).

The most typical mixing twin fluid atomization technique is the air-blast atomization. Air-blast injectors have been widely used and studied (Lefebvre, 1992a, b; Clack et al., 2004; Hoeg et al., 2008; Bolszo and McDonell, 2009; Batarseh et al., 2010). In this technique, air and liquid are supplied separately to the injector, and mixing takes place downstream of the 
nozzle orifice, externally. The liquid discharges through a circular orifice, while the air is supplied through an annular slot around the periphery, resulting in a conical discharge pattern. The main atomization technique is shear interaction caused by high relative velocities between the air and liquid. A liquid jet is exposed to a stream of air flowing at high velocities, which impinge on the liquid jet outside the discharge orifice, producing threads and ligaments. According to Lefebvre (1989), their initial hydrodynamic instabilities are augmented by aerodynamics disturbances, so that they expand away from the nozzle and their thickness slenderizes. When the ligaments collapse, droplets are produced. According to Lorenzetto and Lefebvre (1977), the air-blast injector produces finer droplets as the supply pressure or mass flow rate of the atomizing air is higher, which also increases the power requirement of the atomizer. However, the air blast injector performs poorly with fuels of high kinematic viscosity, creating large droplets that burn in diffusion mode to result in high PM, CO, and $\mathrm{NO}_{x}$ emissions.

Another typical atomization technique of internal mixing type is known as effervescent atomization (Lefebvre, 1988; Lefebvre et al., 1988). A pressurized gas is injected into the bulk liquid in a mixing chamber, upstream of the discharge orifice. The injected gas forms bubbles to produce a two-phase mixture that flows through the orifice. They are expanded quickly when the mixture is exposed to a low-pressure zone at the injector exit, shattering the liquid into droplets. There have been many studies reported in the literature involving effervescent injectors over a range of air-to-liquid mass and liquid flow rates (Lörcher et al., 2005; Konstantinov et al., 2010). According to Sovani et al. (2001), compared with an air blast injector, effervescent ones present advantages like the formation of a spray with finer droplets over a wide range of operating conditions, even for less refined fuels; the injector performance is relatively insensitive to the liquid kinematic viscosity; the larger diameter of the orifice alleviates clogging problems and simplifies fabrication.

Gañan-Calvo (2005) describes the flow-blurring injector, or blurry injector, a novel twin fluid atomization technique, which exploits the advantages of internal and external mixes. This injection method presents several advantages over other injectors, such as formation of a uniform spray, better atomization, high atomization efficiency, robustness, excellent fuel vaporization and mixture with air, and potential for the application in compact combustion systems that can be used as portable power sources. Also, for a specified liquid flow rate and total energy input, the flow-blurring injector creates about 5 to 50 times more droplet surface areas than any other pneumatic injector of the "plain-jet air blast" type. Figure 1 presents the scheme of the flow-blurring injector.

The flow-blurring injector consists of a fuel tube and an exit orifice both of diameter (d). The concept behind flowblurring atomization is that the air is forced through a small gap between the fuel tube exit and a coaxial orifice located $\mathrm{H}$ distance downstream the fuel tube. As shown in Fig. 1, when $H / d<0.25$, part of the air is forced a short distance into the fuel tube and the remaining produces shear layer as it leaves the injector orifice enhancing the atomization process. The back flow of air at the tip of the fuel tube results in a twophase turbulent flow passing through a positive pressure field. This mixture undergoes sudden decrease in pressure, while exiting through the injector orifice. Due to the significant pressure decrease, air bubbles in the two-phase flow expand and shatter the liquid into fine droplets. The flow-blurring injector is capable of producing internal and external mixes of the two phases simultaneously, providing then superiority over other injectors.

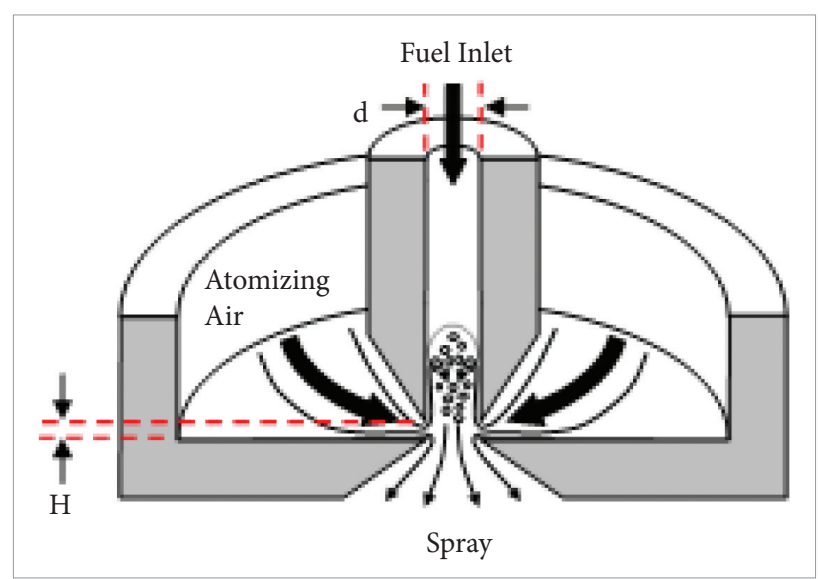

Figure 1. Scheme of the flow-blurring injector (Dent, 2012).

Combustion experiments by Simmons et al. (2008) demonstrated that the flow-blurring injector has the ability to effectively atomize high-viscosity vegetable oil. Furthermore, the fuel supply tube diameter of the injector could alleviate problems of clogging while incurring a lowpressure drop. Panchasara et al. (2009) experimentally compared a flow-blurring with a commercial air blast 
injector, using kerosene and diesel burning in a swirl stabilized combustor operated at atmospheric conditions, and verified that for such fuel and atomizing air flow rates, the flow-blurring injector produced three to five times lower $\mathrm{NO} x$ and $\mathrm{CO}$ emissions as compared to the air blast injector. Reduction in emissions was attributed to improved fuel atomization that resulted in a decrease in the mean droplet size for the flow-blurring injector.

Sadasivuni and Agrawal (2009) used the flow-blurring injector in a compact combustion system with a counter flow heat exchanger. The volumetric energy density of the system was substantially higher than that of the concepts previously developed. Heat release rate of up to $460 \mathrm{~W}$ was achieved in a combustor volume of $2.0 \mathrm{~cm}^{3}$. The combustion system produced clean, compact, quiet, distributed, and attached flat flame. No soot or coking problems were experienced during or after combustor operation on kerosene fuel. Simmons and Agrawal (2010) used laser sheet visualization and a phase Doppler particle analyzer to obtain the spray characteristics of a flow-blurring injector, operating with a configuration where $H / D=0.23$ and using as working fluids water and air. The authors also compared the performance of such injector with that of an air blast and from the results, they concluded that the flow-blurring injector can effectively atomize liquids at relatively low air-to-liquid mass ratio (ALR) compared to the air-blast injector, while reducing the pressure drop penalty in the atomizing air line.

Rapid fuel vaporization and mixing with oxidizer are key requirements for liquid-fueled small-scale combustion systems. Thus, the optimization of combustion systems is very attractive, since the use of non-renewable liquid hydrocarbon fuels is responsible for most of the energy production and pollutants emissions. Therefore, improvements in the design and operation of this equipment are essential for current environmental and energy requirements.

The flow-blurring injector is effective in generating a fine spray for liquid fuels in mesoscale systems to promote vaporization. Therefore, this work presents the characterization of hydrous ethanol sprays formed by a blurry injector with a divergent exit. The liquid and air mass flow rates were measured experimentally and, since lower flow rates and pressures were adopted, the injector will be considered for applications in a flameless compact combustion chamber. Flameless combustion is a homogeneous low temperature burning process leading to strongly reduced pollutant emissions and higher efficiency compared to the traditional processes (Wünning and Wünning, 1997). Experiments are conducted for different liquid and air mass flow rates at ambient conditions of temperature and pressure.

\section{EXPERIMENTAL SETUP}

\section{BLURRY INJECTOR}

Figure 2 shows the injector developed that will be possibly used in a flameless compact combustor. The blurry injector consisted of a central liquid tube $(d=0.5 \mathrm{~mm})$ and a coaxial atomizing air passage with $6 \mathrm{~mm}$ inner diameter. The two-phase mixture exits through the orifice of diameter $(d=0.5 \mathrm{~mm})$ in the discharge plate located, such that $H=0.125 \mathrm{~mm}$. As discussed, this geometry creates a turbulent mixing between the air and liquid phases at the tip of the liquid supply tube to produce a fine spray.

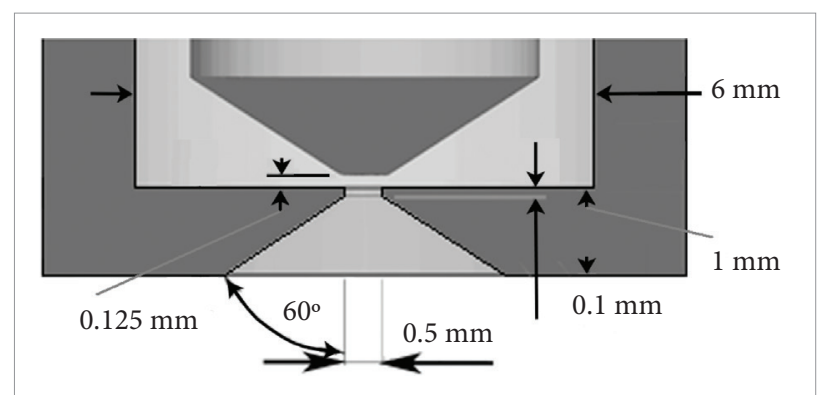

Figure 2. Schematic representation of the blurry injector.

\section{Test bench}

Compressed air was used as the atomizing gas and was supplied from a high-pressure cylinder, controlled by a needle valve, and measured by a calibrated flow meter with an uncertainty of \pm 1.5 standard liters per minute (slpm). The flow rates of hydrous ethanol were measured by rotameters, with the uncertainty in the measurements being $\pm 2 \%$. Supply pressure in the fuel and atomizing air lines were measured using pressure transducers at locations depicted in Fig. 3.

The average droplet diameters and size distribution of the spray were measured using a laser diffraction system 


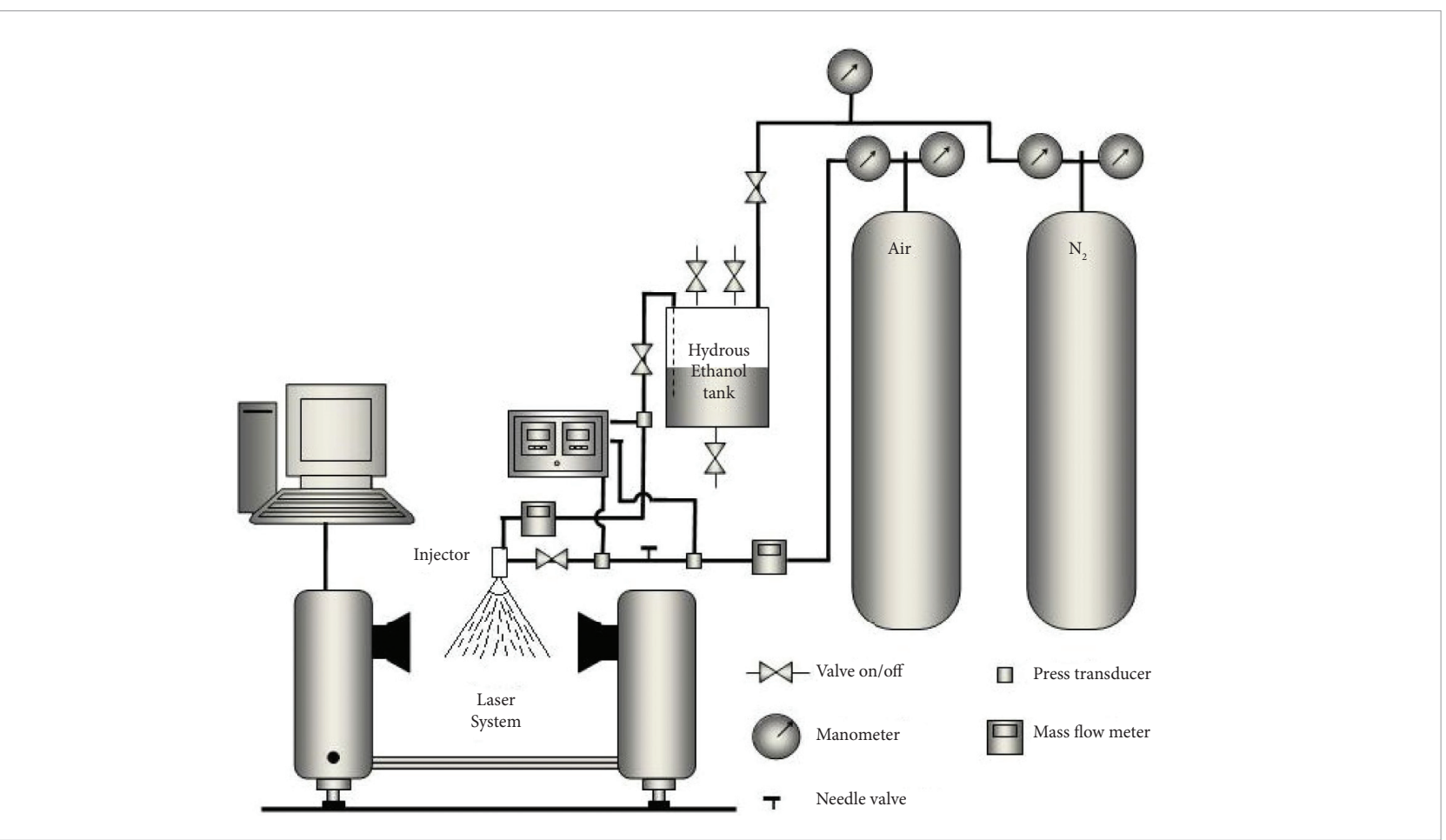

Figure 3. Schematic representation of the test bench.

(Malvern Spraytec ${ }^{\circledR}$ ) at atmospheric conditions. The operating principle of this system is the laser scattering produced by the droplets. The laser diffraction system can measure droplet diameters from 0.1 to $2,000 \mu \mathrm{m}$ with accuracy of $\pm 1 \%$ of full scale (specified by the manufacturer). It could measure the droplet size and distribution of sprays with obscurations up to $95 \%$ and calculates spray average properties along a sight line across the spray.

The laser measurements were taken $50 \mathrm{~mm}$ downstream of the injector exit, where the spray drop size was constant further downstream. The centre of the spray was positioned at the laser beam centre, so it could be fully covered by the laser beam.

Table 1 shows the properties of the hydrous ethanol. Density $\rho$, surface tension $\sigma$, and dynamic viscosity $v$ were determined by measurement in laboratory.

Table 1. Properties liquid fuel at $95 \mathrm{kPa}$.

\begin{tabular}{c|c|c|}
$\begin{array}{c}\text { Surface tension, } \sigma \\
(\mathrm{N} / \mathrm{m})\end{array}$ & $\begin{array}{c}\text { Density, } \rho \\
{\left[\mathrm{kg} / \mathrm{m}^{3}\right]}\end{array}$ & $\begin{array}{c}\text { Dynamic viscosity, } \\
\mathrm{v}\left(\mathrm{Ns} / \mathrm{m}^{2}\right]\end{array}$ \\
\hline $0.024^{*}$ & $806.7^{* *}$ & $0.00124^{* *}$ \\
\hline
\end{tabular}

*measured at $299.15 \mathrm{~K}$; **measured at $298.15 \mathrm{~K}$.

\section{RESULTS AND DISCUSSION}

Initially, the liquid flow rate was kept constant and the airflow rate was varied to obtain the variation in ALR in the injector. Then, the liquid flow rate was varied for different values of airflow rate. Air density was calculated considering the supply pressure and temperature of the atomizing air.

\section{PRESSURE DATA}

Figure 4 shows the pressure in the atomizing air line and the pressure in the hydrous ethanol one for different air flow rates. The pressure measured was effectively that drop in the line because the injector was open to the room.

It can be seen in Fig. 4 that the air and liquid pressures in the injector increase with air flow rate being higher. The air pressure ranged from 1.02 and 2.88 bar for air flow rate from 0.082 to $0.24 \mathrm{~g} / \mathrm{s}$, and the liquid pressure varied between 0.94 to $2.34 \mathrm{bar}$ for air flow rate from 0.082 to $0.24 \mathrm{~g} / \mathrm{s}$. The pressure is higher when there is an increase of both air and hydrous ethanol mass flow rates. 

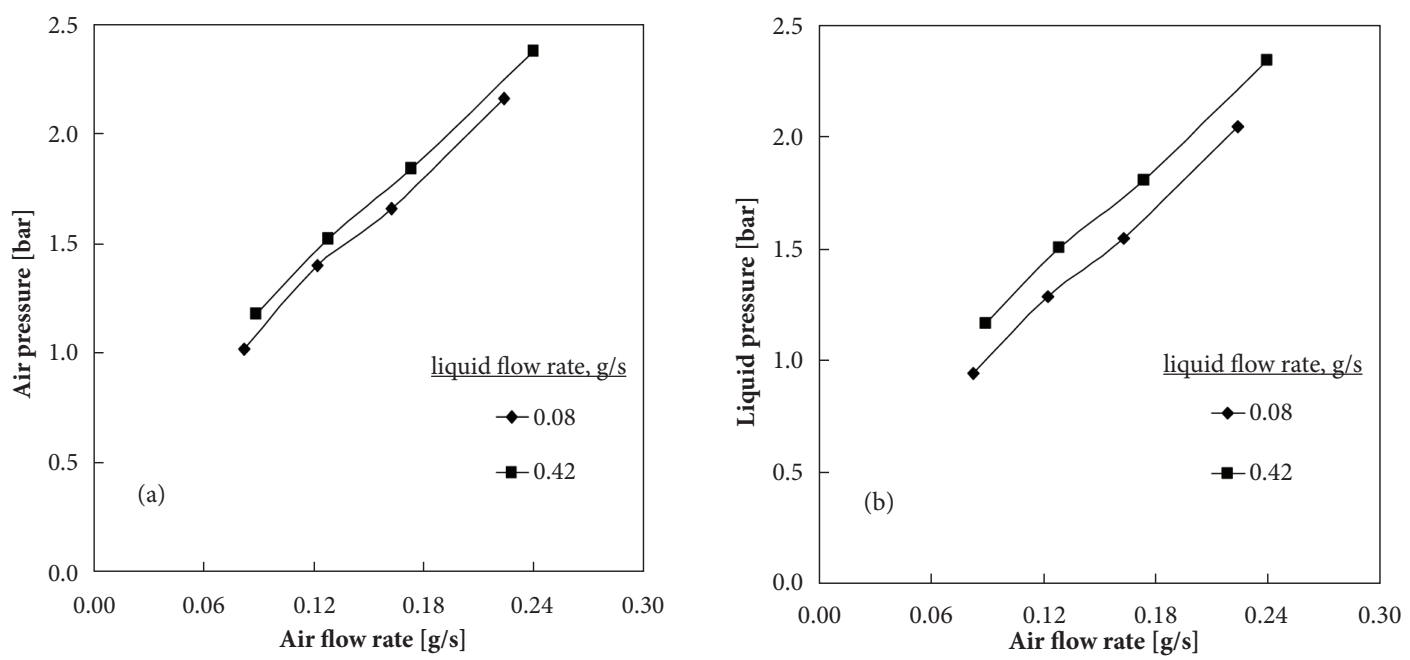

Figure 4. Air and liquid pressures.

\section{AIR-TO-LIQUID MASS FLOW RATIOS}

The ALR for the operational conditions are depicted in Fig. 5. To obtain the plots in Fig. 5 the liquid flow rate was initially kept constant and the air flow rate was varied over a range to obtain the variation in ALR. The liquid flow rate was then varied and the entire procedure was repeated for different values of air flow rate.

It is observed in Fig. 5 that for a given liquid flow rate an increase in the air one leads to an increase in ALR. The data in Fig. 5 also show an increase in ALR with a decrease in the liquid flow rate. The reason for the increase in ALR can be attributed to the fact that with the decrease in the area occupied by the liquid due to the decrease in its flow rate the area available for air flow increases, doing the same in the air flow rate. For the liquid flow rates analyzed, it was verified that the air flow rate varied between 0.082 and $0.24 \mathrm{~g} / \mathrm{s}$ and the ALR was seen changing from 0.21 to 2.88 .

\section{DISCHARGE COEFFICIENT}

The discharge coefficient is the ratio between the experimental mass flow rate and the maximum theoretical mass flow rate of the liquid in the injector. It is given by Eq. 1 (Delmeé, 1983):

$c_{d}=\frac{m_{l}}{A \sqrt{2 \rho_{l} \Delta P_{l}}}$

where $c_{\mathrm{d}}$ is the discharge coefficient of the liquid; $m_{l}$ the experimental liquid mass flow rate, $\mathrm{kg} / \mathrm{s} ; A$ is the total

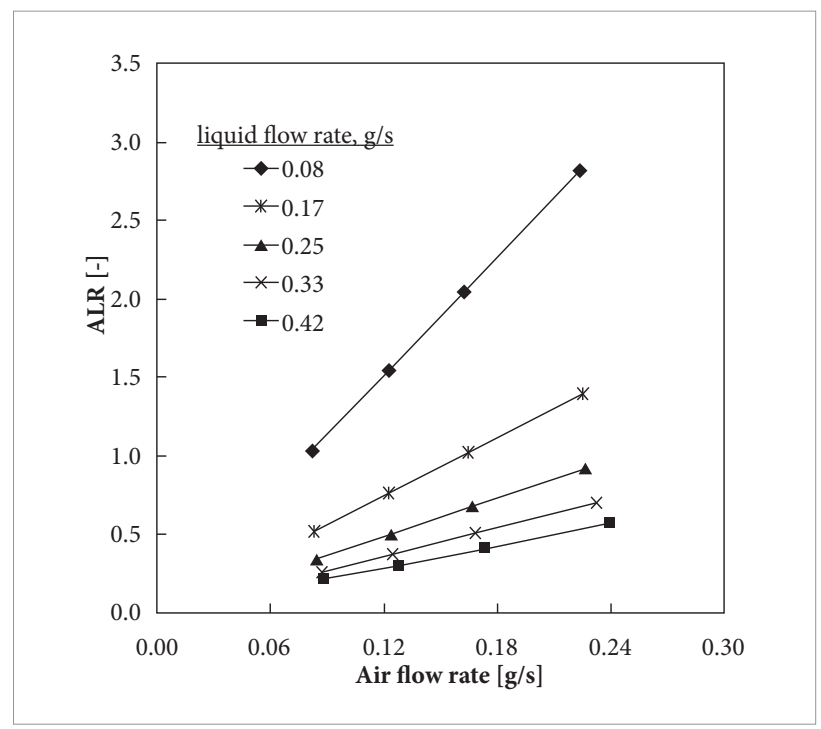

ALR: air-to-liquid mass ratio.

Figure 5. Air-to-liquid mass flow ratio.

cross-sectional area of the discharge orifices, $\mathrm{m}^{2} ; \Delta P_{l}$ is the pressure difference of the liquid flow across the nozzle, Pa; and $\rho_{l}$ is the density of the liquid, $\mathrm{kg} / \mathrm{m}^{3}$. At each test condition, the discharge coefficient was determined by substituting into Eq. 1 the measured values of liquid flow rate and pressure drop across the injector, along with injector flow area and liquid density. Figure 6 shows the typical curve of the discharge coefficients versus ALR.

It is seen in Fig. 6 that for a given liquid flow rate the discharge coefficient decreases with an increase in ALR. Lefebvre (1983) has defined the discharge coefficient to be a measure of the extent to which the liquid flowing through the final discharge orifice 


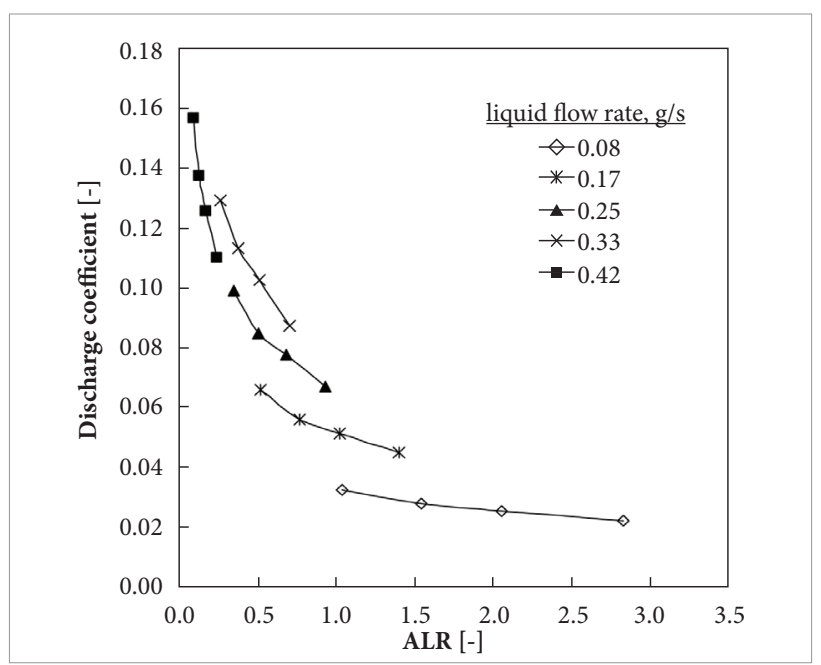

ALR: air-to-liquid mass ratio.

Figure 6. Discharge coefficient versus air-to-liquid mass ratio.

makes full use of the available flow area. Therefore, the discharge coefficient depends on the amount of flow area available for the liquid phase. As ALR increases, the flow area available for liquid decreases and $C_{d}$ is inferior. The rate of change in discharge coefficient decreases with an increase in ALR, which is responsible for a slower rate of decrease in the liquid flow rate at higher values of ALR as seen in Fig. 6. The values of discharge coefficient shown in Fig. 6 vary from 0.022 and 0.157 over the entire operating range.

\section{DROPLET DIAMETER DATA}

Different characteristic diameters can be obtained to represent a spray. In this work, the Sauter mean diameter (SMD) and the mass median diameter (MMD) were obtained with aid of the laser system. The SMD is the droplet size that possesses a volume-to-surface-area ratio proportional to that of the entire spray, and MMD is the drop diameter such that $50 \%$ of the total mass of spray consists of droplets of smaller diameter.

Figure 7 illustrates the effect of ALR on the SMD and MMD at different liquid mass flow rates for hydrous ethanol.

The results show that the droplet size is strongly influenced by the ALR. The data presented in Fig. 7 conclude that the droplet size decreases with an increase in ALR for a given liquid flow rate. It is verified that a decrease in liquid mass flow rate causes a decreasing in the mean drop size. The higher the ALR is, the higher the air flux will be, and then a larger smashing energy can be provided for liquid atomization. It can be speculated that this decrease in the droplet diameter value is due to two effects. First, the increase in ALR increases the air flow rate and the effective area occupied by air, decreasing the effective area occupied by liquid and liquid flow rate through the injector orifice. Increase in air flow area is beneficial to atomization, because it reduces the area available for the liquid flow, i.e. it squeezes the liquid into thinner films and ligaments as it flows through the injector orifice. Secondly, the increase in ALR is accompanied by one in exit velocities and turbulence inside the injector, resulting in improved atomization.

Figure 8 illustrates the effects of atomizing air velocity on SMD and MMD at different liquid mass flow rates for hydrous ethanol. Table 2 shows the ranges of ALR, air velocity, SMD, and MMD measured.
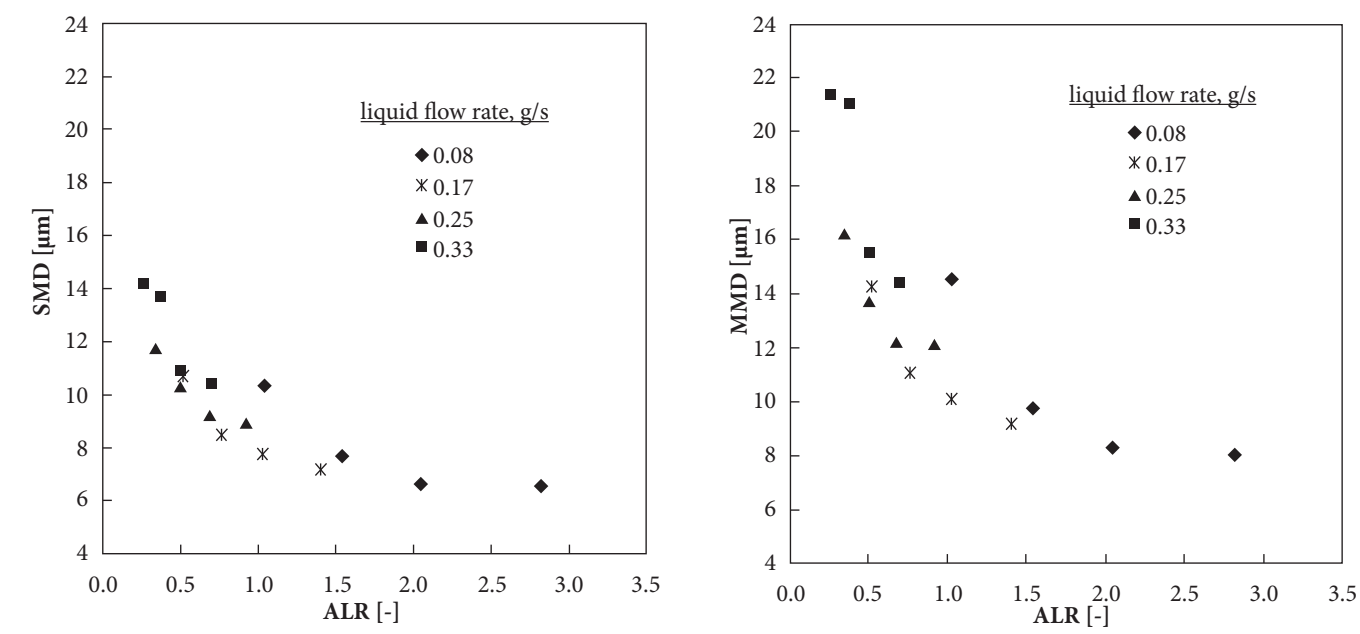

SMD: Sauter mean diameter; MMD: mass median diameter; ALR: air-to-liquid mass ratio.

Figure 7. Influence of air-to-liquid mass ratio on Sauter mean and mass median diameters. 
Table 2. Ranges of air-to-liquid mass ratio, air velocity and average diameters.

\begin{tabular}{|c|c|c|c|c|}
\hline $\begin{array}{c}\text { Liquid mass flow rate } \\
{[\mathrm{g} / \mathrm{s}]}\end{array}$ & $\begin{array}{c}\text { ALR } \\
{[-]}\end{array}$ & $\begin{array}{c}\text { Air velocity } \\
{[\mathrm{m} / \mathrm{s}]}\end{array}$ & $\begin{array}{c}\text { SMD } \\
{[\mu \mathrm{m}]}\end{array}$ & $\begin{array}{c}\text { MMD } \\
{[\mu \mathrm{m}]}\end{array}$ \\
\hline 0.08 & $1.04-2.82$ & $176.96-304.49$ & $10.37-6.59$ & $14.53-7.97$ \\
\hline 0.17 & $0.52-1.40$ & $181.37-309.27$ & $10.71-7.20$ & $14.27-9.17$ \\
\hline 0.25 & $0.35-0.93$ & $185.04-313.30$ & $11.75-8.97$ & $16.27-12.13$ \\
\hline 0.33 & $0.26-0.70$ & $188.27-316.82$ & $14.17-10.41$ & $21.37-14.40$ \\
\hline
\end{tabular}

SMD: Sauter mean diameter; MMD: mass median diameter; ALR: air-to-liquid mass ratio.
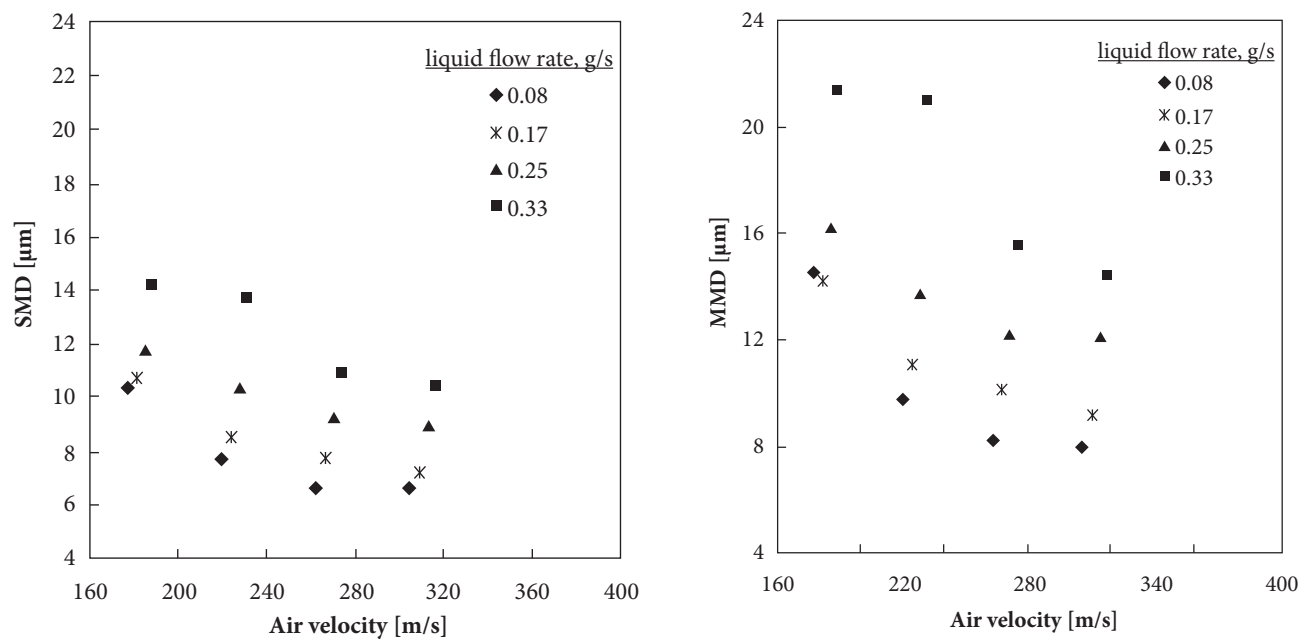

SMD: Sauter mean diameter; MMD: mass median diameter.

Figure 8. Influence of air velocity on Sauter mean and mass median diameters.

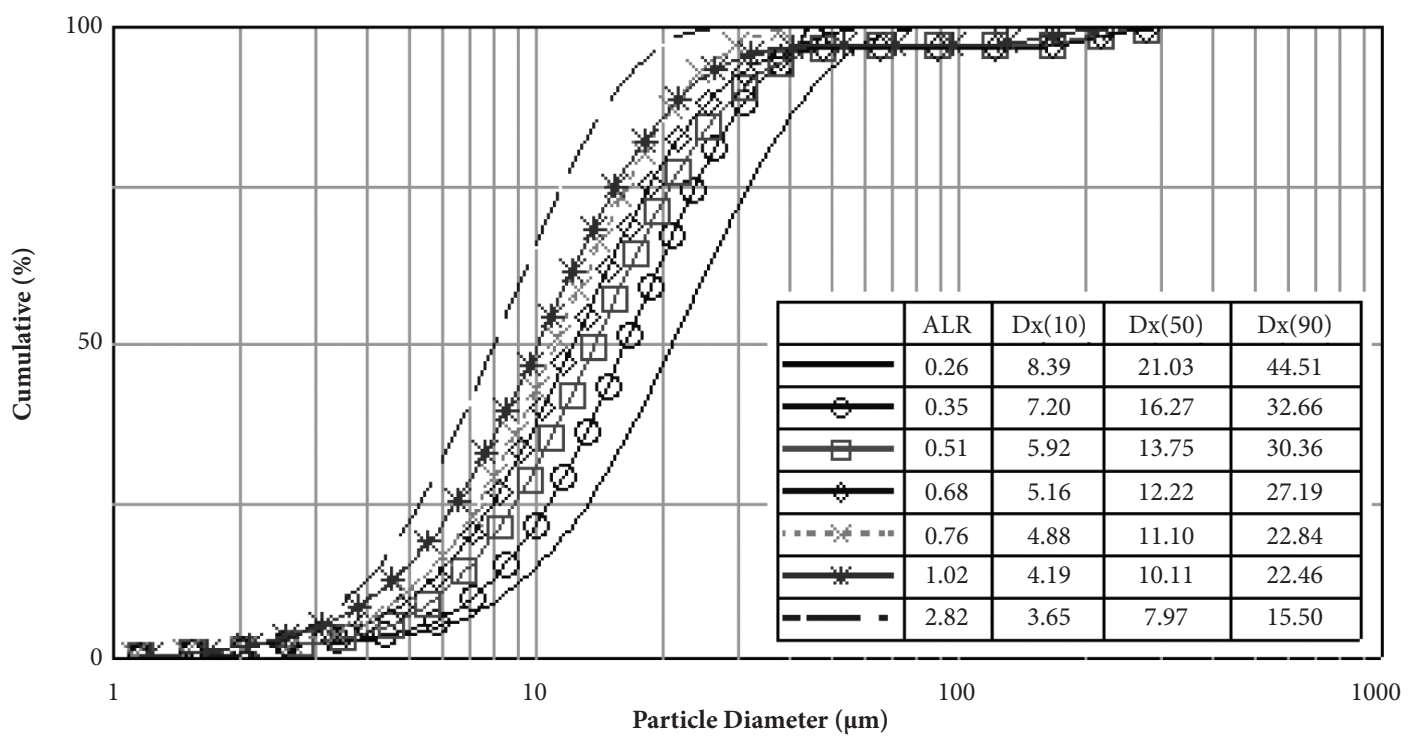

Figure 9. Cumulative drop size distributions. 
Figure 9 depicts the effects of ALR on cumulative drop size distributions and on representative diameters, Dx10, Dx50 and Dx90, i.e. the drop diameters such that 10, 50 and $90 \%$ of total liquid volume are in drops of smaller diameter.

The particle size distribution at a low ALR depicts the presence of larger droplets compared to the case of higher ALR, where the percentage of smaller size droplets have increased significantly, reflecting an improved atomization at higher ALR. As expected, it was verified that an increase in ALR leads to a decrease in droplet diameters, since the increase in air flow results in better atomization.

\section{CONCLUSIONS}

A blurry injector has been developed for applications in a compact flameless combustion chamber, and the spray characteristics were obtained for injection of hydrous ethanol. The discharge coefficient is seen to decrease with an increase in ALR, which is attributed to the decrease in an available area for liquid flow with increasing air flow. The average droplet diameters decreased significantly with increasing ALR and air velocity. Air and liquid injection pressures were higher, approximately, linearly with increasing air flow rates.

\section{REFERENCES}

Batarseh, F.Z., Roisman, I.V. and Tropea, C., 2010, "Characterization of a spray generated by an airblast atomizer with prefilmer", Atomization and Sprays, Vol. 20, No 10, pp. 887-903.

Bolszo, C.D. and McDonell, V.G., 2009, "Evaluation of plain-jet air blast atomization and evaporation of alternative fuels in a small gas turbine engine application", Atomization and Sprays, Vol. 19, No 8, pp. 771-785.

Clack, H. L., Koshland, C. P., Lucas, D. and Sawyer, R. F., 2004, "Development of an air-blast atomizer for independent control of droplet size and spray density", Atomization and Sprays, Vol. 14, No 3, pp. 265-288.

Delmeé G.J., 1983, "Manual de Medição de Vazão", São Paulo, Editora Edgard Blucher, 474 p.

Dent, T.J., 2012, "Mesoscale power generation incorporating heatrecirculation, porous inert media, and thermoelectric modules", Ph.D. Thesis, University of Alabama, Alabama, USA.

Gajdeczko, B.F., Luff, J., Dryer, F.L. and Lavid, M., 2000, "Laser Ignition of Liquid Oxygen/Ethanol Propellants", Twenty-Eighth Symposium (International) on Combustion, Abstracts of Work in Progress Poster Presentations (No. 2-B20), The Combustion Institute, Pittsburgh, PA, $244 \mathrm{p}$.

Gañán-Calvo, A.M., 2005, "Enhanced Liquid Atomization: From FlowFocusing to Flow-Blurring", Applied Physics, Letters 86.

Hoeg, D.P., Wang, Z., Friedman, P. D. and Laoulache, R. N., 2008, "Investigation of a coaxial air-blast atomizer using particle image velocimetry and computational fluid dynamics", Atomization and Sprays, Vol. 18, No 8, pp. 739-759.

Konstantinov, D., Marsh, R., Bowen, P. and Crayford, A., 2010, "Effervescent atomization for industrial energy-technology review", Atomization and Sprays, Vol. 20, pp. 525-552.

Lefebvre, A.H., 1983, "Gas Turbine Combustion", Hemisphere, Washington, D.C.

Lefebvre, A.H., 1988, "A novel method of atomization with potential gas turbine applications", Defense Sciences Journal, Vol. 38, pp. 353-362.
Lefebvre, A.H., 1989, “Atomization and Sprays”, Hemisphere, New York. Lefebvre, A.H., 1992a, "Energy consideration in twin-fluid atomization", Journal of Engineering for Gas Turbine, Vol. 114, pp. 89-96.

Lefebvre, A.H., 1992b, "Twin Fluid Atomization: Factors Influencing Mean Drop Size”, Atomization and Sprays, Vol. 2, No 2, pp. 101-119.

Lefebvre, A.H. et al., 1988, "Spray characteristics of aerated-liquid pressure atomizers", Journal of Propulsion and Power, Vol. 4, pp. 293-298.

Lörcher, M., Schmidt, F. and Mewes, D., 2005, Effervescent atomization of liquids, Atomization and Sprays, Vol. 15, pp. 145-168.

Lorenzetto, G.E. and Lefebvre, A.H., 1977, "Measurements of Drop Size on a Plain-Jet Airblast Atomizer", AIAA Journal, Vol. 15, Issue 7, pp. 1006-1010.

Panchasara, H.V., Sequera, D.E., Schreiber, W.C. and Agrawal, A.K., 2009, "Emissions Reductions in Diesel and Kerosene Flames Using a Novel Fuel Injector", Journal of Propulsion and Power, Vol. 25, No. 4, pp. 984-987.

Sadasivuni, V. and Agrawal, A.K., 2009, "A novel meso-scale Combustion System for Operation with Liquid Fuels", Proceedings of the Combustion Institute, Vol. 32, pp. 3155-3162.

Simmons, B. and Agrawal, A.K., 2010, "Spray Characterization of a Flow-Blurring Atomizer", Atomization and Sprays, Vol. 20, pp. 821-835.

Simmons, B.M., Panchasara, H.V. and Agrawal, A.K., 2008, "Effect of fuel injection concept on combustion performance of liquid fuels", Proceedings of 2008 Technical Meeting of the Central States Section of The Combustion Institute, Combustion Institute, Pittsburgh.

Sovani, S.D., Sojka, P.E. and Lefebvre, A.H., 2001, "Effervescent atomization", Progress in Energy and Combustion Science, Vol. 27, pp. 483-521.

Wünning, J.A. and Wünning, J.G., 1997, "Flameless Oxidation to Reduce Thermal No-formation", Progress in Energy and Combustion Science, Vol. 23, Issue 1, pp. 81-94. 